\title{
Dynamic Analysis of Double-Skin Composite Steel Plates
}

\author{
Mohamedien, A.R ${ }^{1}$, Omer, A. $\mathrm{A}^{2}$ \\ ${ }^{\prime}$ (Civil Engineering Department, Military Technical College. / Cairo, Egypt.) \\ ${ }_{2}^{2}$ (Mechanical Engineering Department, Military Technical College / Cairo, Egypt.)
}

\begin{abstract}
Double Skin Composite (DSC) plates are subjected to impact required to cause complete perforation and the accompanied failure modes are investigated. The amount of energy absorbed is calculated by capturing the residual velocity of penetrator after perforating the lower plate. The difference in initial kinetic energy and residual kinetic energy is the amount of energy absorbed by the panel. In the present paper a non-linear threedimensional finite element models for Double Skin Composite panels subjected to dynamic loading is introduced. Pilot model is used to investigate the failure pattern in the composite panel when subjected to impact loads by rigid steel penetrator, while the other models are used to analyze the energy absorption capacity of such system when perforated. Results showed that such elements have good ability of absorbing energy when subjected to perforation, due to ductility of lower plate skin and vertical stiffness of lower shear studs.
\end{abstract}

Keywords: Double skin composite; Steel Plates; Concrete; Impact; Dynamic loading; Shear studs.

\section{Introduction}

The main problems facing the usage of reinforced concrete to resist impact loading that may cause penetration or perforation of slabs in buildings, shelters,....etc are much smallness in ductility of concrete slabs and needing of big slab thickness or great reinforcing steel ratio in slab section [1]

H.D. Wright et. al. [2,3], investigated the experimental behavior of DSC elements by early pilot tests which were carried out on individual half scale and full scale models. The tests divided into three series dealing with beam behavior, column and eccentrically loaded column behavior and beam column behavior.

T. M. Roberts et. al. [4], used the static test to investigate the behavior of DSC beams under series of quasi-static load tests. Their search also focused on the observed modes of failure that were yielding of tension and compression steel plates and slip of the tension plate connectors. All beams exhibited reasonably ductile behavior and many of the beams exhibited extensive shear cracking during latter stages of the tests. However, the shear cracking did not precipitate failure.

N. E. Shanmugam, et. al. [5], describe finite element modeling of the ultimate load behavior of simply supported DSC slabs. The effects of shear studs were modeled indirectly by adjusting the shear stress parameter for the core material. The study provided a transformed section having the same structural stiffness and load carrying capacities. The results of the model in their study were very close to the results of their experimental tests except in some specimens, the reason was that the absence of a direct simulation of shear studs in the model. Also the buckling of steel plates did not appear.

M. Xie et al. [6] investigated the shear behavior of friction-welded bar-plate connections embedded in concrete to model a push-out test with direct representation of shear connectors by solid elements.

Perry et al. [7] discussed the factors influencing the response of fiber-reinforced concrete slabs to impact and noted that changing the amount of fiber reinforcement may change the mode of failure of the concrete. The unreinforced concrete tends to fail by shear punching. Steel-fiber reinforced concrete tends to fail by flexure and crushing of the concrete.

Corbett \& Reid [8] investigated the response of steel - grout sandwich plates to projectile impact; it was shown that sandwich plates made up of two $1 \mathrm{~mm}$ thick steel skins separated by grout fillers with thickness ranging from 3 to $40 \mathrm{~mm}$ were not efficient enough to withstand projectile impact in terms of energy absorbed per density of steel plates. Corbett et al [9] investigated the resistance of steel-concrete sandwich tubes to penetration from hardened steel indentor. Concrete tubes were claded on their outer and inner diameters with $1 \mathrm{~mm}$ thick steel skins and subjected to quasi static and dynamic loadings. The tested tubes had an inner diameter of $120 \mathrm{~mm}$, concrete fillers of thickness $10,20,38 \mathrm{~mm}$ were examined. It was shown that the impact resistance of steel - concrete sandwich structures was less sensitive to projectile mass and nose shape than monolithic steel structures. In addition the resistance of the sandwich structures to projectile penetration was seen to be most effective when the rear face skin was undeformed which provides substantial support to the filling medium. 
In the aim of understanding the impact problems and its technical terms, Naik and. Shrirao [10] define the important technical term used in the impact problems, such as the definition of the ballistic limit of target which is the maximum velocity of a projectile at which complete perforation takes place with zero exit velocity.

In the present paper, a non-linear three-dimensional finite element models for Double Skin Composite (DSC) panels subjected to dynamic loading using ABAQUS is introduced. Pilot model was used to investigate the failure pattern in the composite panel when subjected to impact loads by rigid penetrator. The other models were used to analyze the energy absorption capacity of such system when perforated. These models include variation of upper and lower plate thicknesses as well as increasing degree of shear interaction between upper plate and concrete core, increasing degree of shear interaction between lower plate and concrete core. The last model includes concentration of the distribution density of stud shear connectors at the middle of the upper plate. These models were checked first against quasi static, experimental and finite element results [11], [12]. Therefore the purpose of this study is to investigate the change in failure mechanism compared with quasi-static and to investigate the absorbed energy by such panels when subjected to impact by conical shape rigid penetrator.

\subsection{DSC panels dimensions and meshing}

\section{Input Data For Dynamic Analysis}

All panels are of dimensions $(1000 \mathrm{~mm} \times 1000 \mathrm{~mm})$ and have concrete core thickness of $50 \mathrm{~mm}$, except in the pilot specimen, where the concrete core was $80 \mathrm{~mm}$. Table (1) shows the details of all specimens, while Figure (1) shows the dimensions and studs distribution across the plates. The composite slabs were modeled as non-linear three-dimensional models. The top and bottom steel plates were modeled using fournodes reduced integration shell elements with large strain formulation; whereas the concrete core was modeled using eight nodes solid element with holes similar to those of shear studs that were embedded in concrete. The shear studs were modeled by using eight nodes solid element. The penetrator was modeled as an analytical rigid surface. Assembly techniques were used to compose upper plate skin with upper shear connectors and lower plate skin with lower shear connectors. The Concrete core was imposed between the steel plates, while the analytical rigid part is adjusted in the center of upper steel plate. Shell elements of upper and lower steel plates were divided into regions of different mesh size. At the middle of the shell the mesh is divided into two strips with fine mesh for increasing the accuracy of the results at the regions around the penetrator. Solid elements of shear connectors were finely meshed by approximate element side size of $(2.5 \mathrm{~mm})$. Solid elements of concrete core were divided into regions of different mesh sizes, such that the regions of stud holes were the same as those of the steel plates. The core was meshed with the same fine mesh in the two strips (in both directions) at the middle while the rest of core was meshed by mesh size of $(35 \mathrm{~mm})$. Figure (2) shows the assembly of penetrator with the composite slab after mesh.

Table1 Dimensions and stud distribution of all specimens

\begin{tabular}{|c|c|c|c|c|c|c|c|}
\hline \multirow{2}{*}{ Specimen } & \multirow{2}{*}{$\begin{array}{l}\text { Concrete } \\
\text { core } \\
\text { thickness } \\
(\mathbf{m m})\end{array}$} & \multicolumn{2}{|c|}{ Upper plate } & \multicolumn{2}{|c|}{ Lower plate } & \multirow{2}{*}{$\begin{array}{c}\text { Stud } \\
\text { length } \\
(\mathrm{mm})\end{array}$} & \multirow{2}{*}{$\begin{array}{c}\text { Shank } \\
\text { diameter } \\
(\mathrm{mm})\end{array}$} \\
\hline & & $\begin{array}{l}\text { thickness } \\
(\mathrm{mm})\end{array}$ & $\begin{array}{c}\text { No. of Studs } \\
\text { per row }\end{array}$ & $\begin{array}{l}\text { thickness } \\
(\mathrm{mm})\end{array}$ & $\begin{array}{c}\text { No. of Studs } \\
\text { per row }\end{array}$ & & \\
\hline Pilot test & 80 & 3 & 3 & 3 & 4 & 35 & 8 \\
\hline DSC1 & 50 & 4 & 3 & 2 & 3 & 35 & 8 \\
\hline DSC2 & 50 & 2 & 3 & 4 & 3 & 35 & 8 \\
\hline DSC3 & 50 & 2 & 7 & 2 & 3 & 35 & 8 \\
\hline DSC4 & 50 & 2 & 3 & 2 & 7 & 35 & 8 \\
\hline DSC5 & 50 & 2 & 5 & 2 & 3 & 35 & 10 \\
\hline
\end{tabular}

Plate Thikness $2 \mathrm{~mm} \quad$ DSC 1

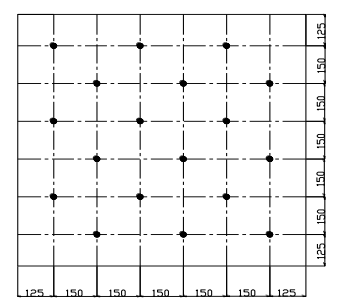

Bottom plate
Plate Thikness $4 \mathrm{~mm}$

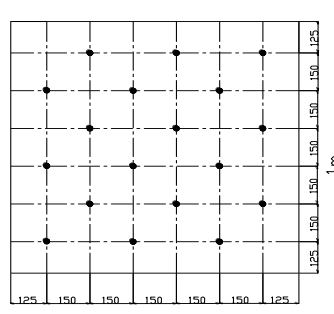

Upper plate

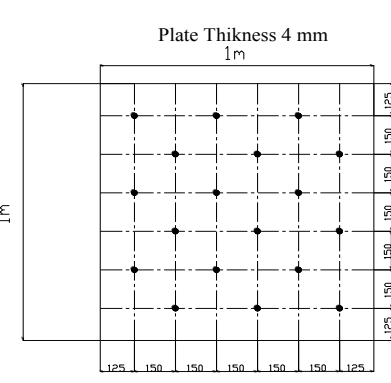

Bottom plate
DSC2

Plate Thikness $2 \mathrm{~mm}$

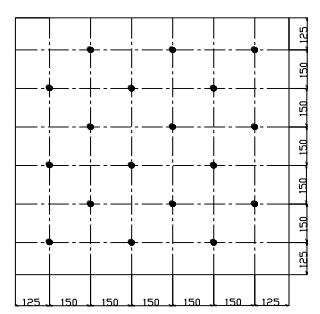

Upper plate 
DSC3

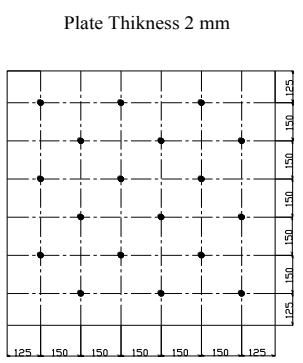

Bottom plate

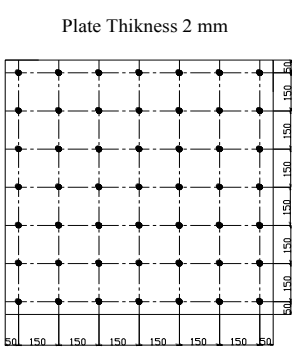

Upper plate

Plate Thikness $2 \mathrm{~mm}$

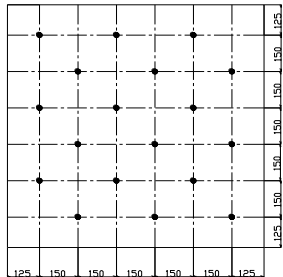

Bottom plate

DSC4

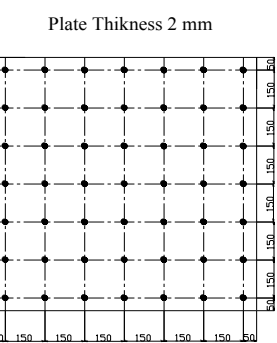

Bottom plate
Plate Thikness $2 \mathrm{~mm}$

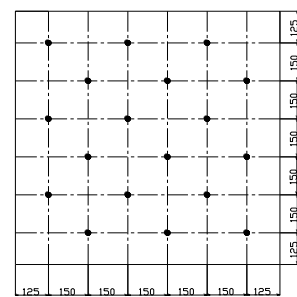

Upper plate

DSC5

Plate Thikness $2 \mathrm{~mm}$

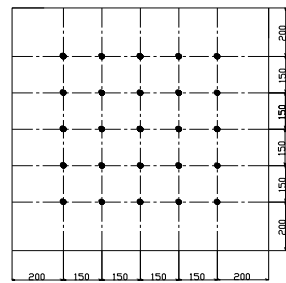

Upper plate

All dim. in mm

Fig.1 Dimensions and stud distribution across the plates of DSC models

\subsection{Material Modeling}

Steel was assumed to behave as an elasto-plastic material in both tension and compression. The material properties of steel were specified using elastic and plastic options in the ABAQUS. For penetration problems, the finite element package provided an option of using failure model by defining shear failure value for used material. Concrete was treated as anisotropic material. The specification of concrete core was taken as mentioned in BS 8110 [13]. For case of penetration in concrete the shear failure was assumed at a value of $40 \%$ of its ultimate strength.

\subsection{Loads and Boundary Conditions}

Boundary conditions were applied on the models to represent the case of clamped upper and lower steel plate ends. The upper and lower shell edges were prevented from translations and rotations in all directions. These boundary conditions occurs by applying boundary conditions techniques available on nodes from edge of shell to nodes laying at a distance equal $70 \mathrm{~mm}$ from edges (angle length of upper and lower frames used to clamp steel plates). As shown in Figure (3). Reference point of analytical rigid part was prevented from moving in all directions except in z- direction. The initial velocity is an input given to the reference point of penetrator. The energy absorbed during quasi-static tests [12], were used to obtain the estimated initial value of velocity as follows:-

\section{Absorbed energy from quasi-static experiments $=1 / 2 \mathbf{m}\left(\mathrm{V}_{0}\right)^{2}$}

The mass of penetrator used is equal to $58.75 \mathrm{Kg}$. Table (2) shows the initial velocity values for each panel as calculated from the above relation. 


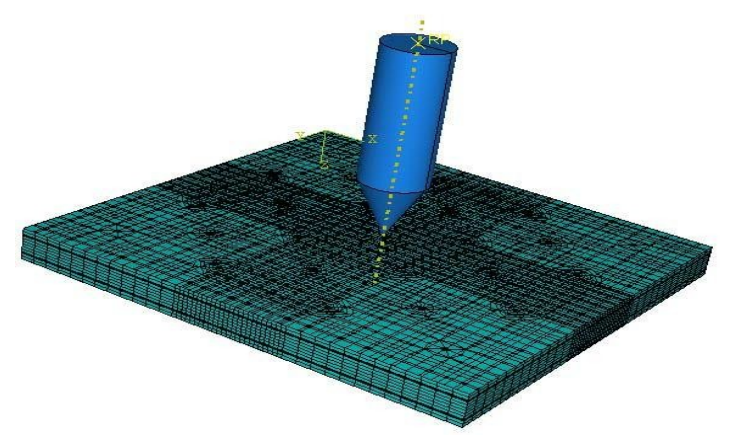

Fig.2 Assembly of penetrator with composite slab

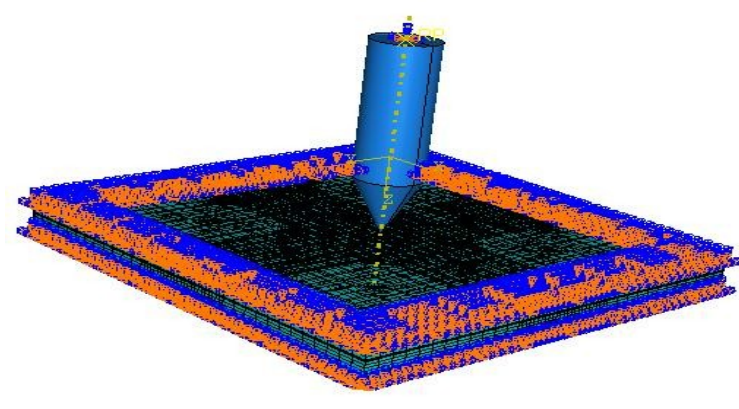

Fig.3 Boundary conditions of composite slab

\section{Dynamic Analysis}

The panels were subjected to impact due to the kinetic energy of the penetrator which is given initial velocity required to cause complete perforation and the accompanied failure modes are investigated. The amount of energy absorbed was calculated by capturing the residual velocity of penetrator after perforating the lower plate. The difference in initial kinetic energy and residual kinetic energy was the amount of energy absorbed by the panel. Failure phases were described by observing the output of stress contours on panel elements during the running steps. The panels were firstly loaded by initial velocity obtained from Table (2) and the results were observed. It was found that the velocities obtained from quasi static test were very high compared with the required ballistic value. When panels loaded with these initial values, it perforated very fast and residual velocity of the penetrator after perforation had very small change. This means that quasi-static results were not good for estimating the energy absorbed by each panel in dynamic analysis. The Initial value of impact velocity was minimized till a clear difference between initial velocity and residual velocity after perforation was observed. For all specimens the initial velocity was $1000 \mathrm{~mm} / \mathrm{sec}$.

Table2 Calculated initial velocity $V_{0}$ from quasi static results [12]

\begin{tabular}{|ccc|}
\hline Specimen & $\begin{array}{c}\text { Quasi-static Absorbed Energy } \\
\text { (K Joule) }\end{array}$ & Estimated initial velocity $\mathbf{V}_{\mathbf{0}}(\mathbf{m} / \mathbf{s})$ \\
\hline Pilot- test & 25.325 & $\mathbf{2 9 . 3 0}$ \\
\hline DSC1 & 20.809 & $\mathbf{2 6 . 6}$ \\
\hline DSC2 & 22.824 & $\mathbf{2 7 . 8 7}$ \\
\hline DSC3 & 11.237 & $\mathbf{1 9 . 5 5}$ \\
\hline DSC4 & 16.555 & $\mathbf{2 3 . 7 5}$ \\
\hline DSC5 & $\mathbf{1 9 . 0 1 7}$ & $\mathbf{2 5 . 4}$ \\
\hline
\end{tabular}

\subsection{Discussions of Failure Pattern}

At first step of impact the upper plate was directly perforated and it moved slightly toward the penetrator because of the effect of inertial force. Figure (4) shows effect of the inertial force on upper plate just after impact and failure shape after perforation. The upper studs had a good role that did not appear in quasistatic analysis case Figure (5), since when the inertial force takes place as a reaction after impact, the upper plate move slightly upward and the upper studs played the role of vertical links and increased the stiffness of the plate. The elements of upper face of concrete failed after first step of impact, but they were much localized and high stress values were plotted as shown in Figure (6). No spalling was observed because of the upper skin covering, which keep the resistance of concrete during the post step of penetration. Concrete core lower surface pained much larger than upper surface especially in lower stud places which ensured the great effect of lower studs in resistance of penetration, since they acted as hangers for the lower plate as seen in Figure (7). Failure in lower studs was very obvious and happened faster than quasi-static case, which caused rotation of studs after failure due to absorbing large energy in very small time as shown in Figures (8) and (9). Investigation of panel motion due to impact was done by capturing the velocity in direction and magnitude for the middle point of lower plate, as shown in Figure (10). The lower plate gained the same value of initial impact velocity and moved downward a distance that gave it dynamic stability, then it rebounded upward due to the inertial force gained from getting large energy in small time. As progress of the penetrator motion downward, lower plate motion started to increase but with slight vibration. 

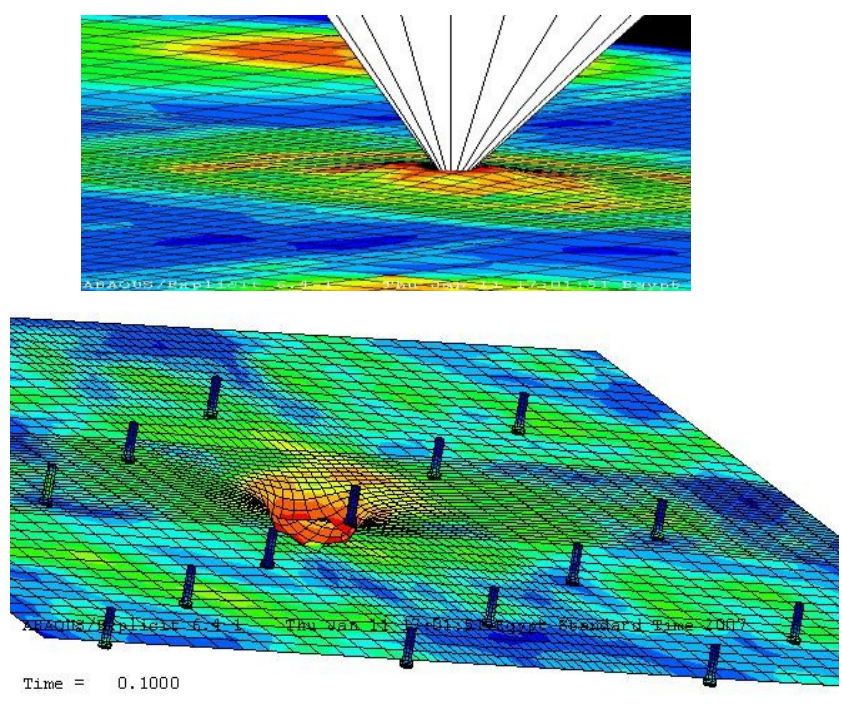

matinn Srale Fartinr: +1.กกПe+กก

Fig.4 Inertial force effect and failure shape of upper plate (dynamic)

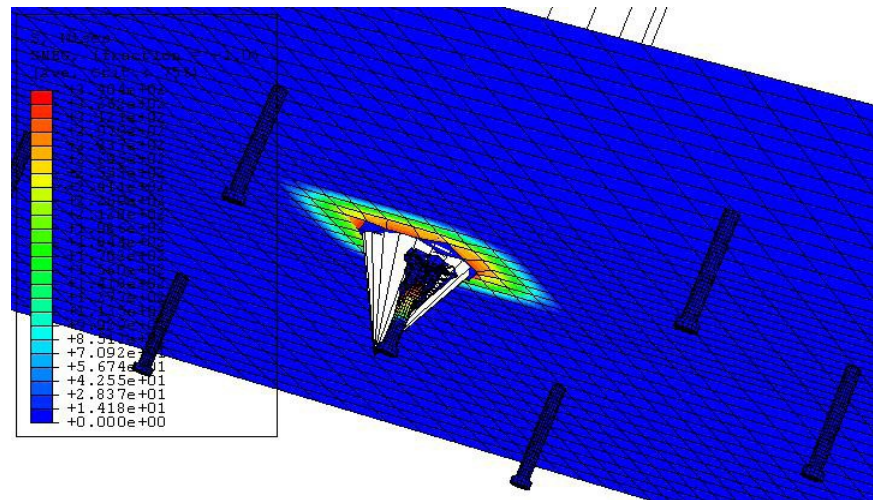

Fig.5 Failure shape of upper plate (quasi-static)

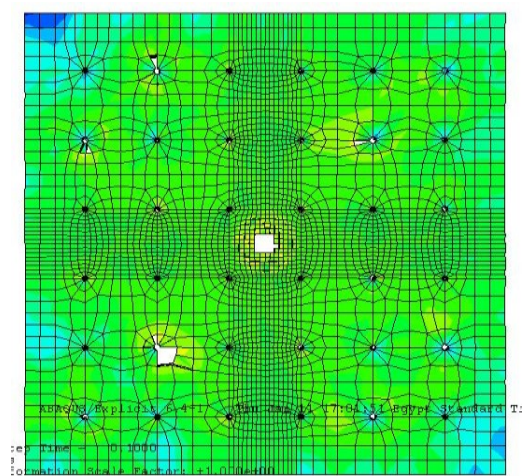

Fig.6 Localized failure of upper concrete face

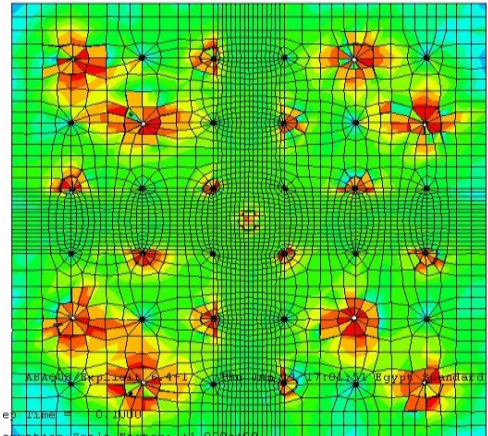

Fig.7 High stress contours in places of Lower studs in Concrete 


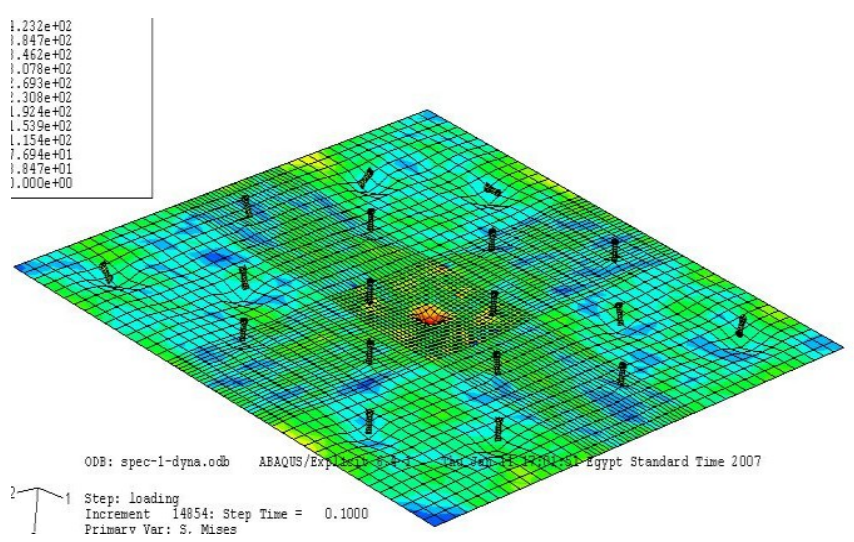

Fig.8 Failure of lower studs (dynamic)

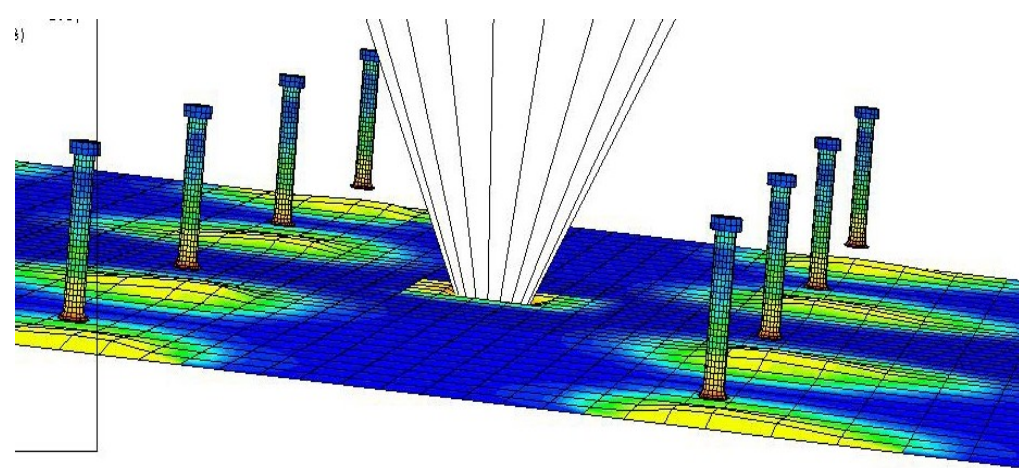

Fig.9 Failure of base element of lower stud (quasi-static)

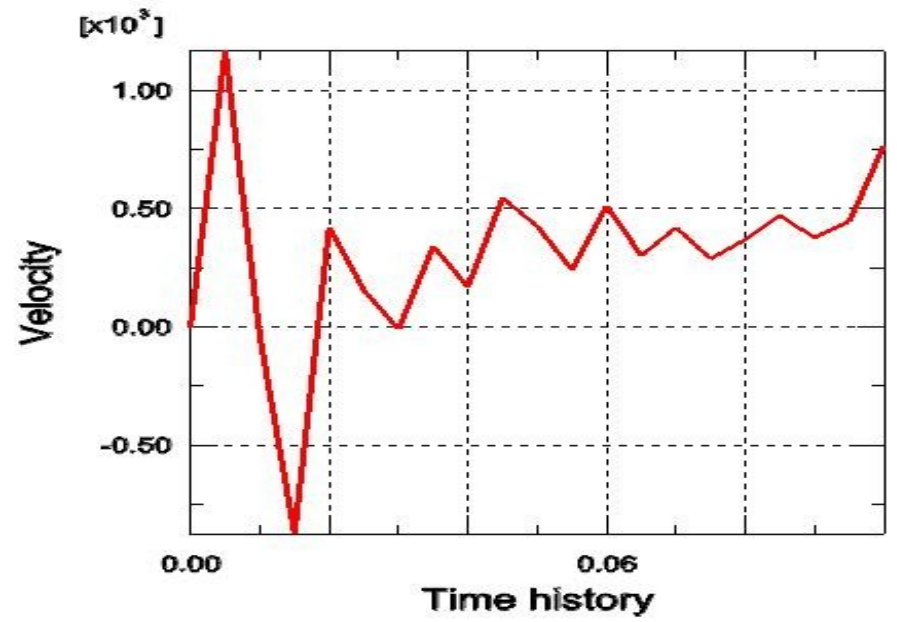

Fig.10 Velocity - Time history of middle point in lower plate

\section{Investigation Of Ballistic Limit And Discussion Of Results}

Ballistic limit is the amount of energy absorbed by the target when subjected to impact by initial velocity and certain mass to have residual velocity equal to zero if succeeded in perforating the total thickness of the target. The initial value of velocity $\left(\mathbf{V}_{\mathbf{0}}\right)$ for all models was taken $1000 \mathrm{~mm} / \mathrm{sec}$ while, the residual velocity $\left(\mathbf{V}_{\mathbf{R}}\right)$ after perforation was captured. Then the ballistic limit of the studied models was calculated from the following relation:-

Absorbed energy for computing ballistic limit $=1 / 2 m\left(V_{0}\right)^{2}-1 / 2 m\left(V_{R}\right)^{2}$ 
Figures $(11,12,13,14$ and 15) show the change of the penetrator velocity versus time history till complete perforation of panel for all models. The end point of curves is the value of residual velocity $V_{R}$ of the penetrator. All results have the same behavior of parabolic decrease in penetrator velocity when the resistances of the panels were faced. All specimens' results were taken in the range of total time history required for perforating the lower plate. In ABAQUS time history or total time does not mean real time but it is an indication for required iterations done by solver to reach dynamic stability between elements on contact during the run.

The analysis of results is arranged into three groups (A), (B) and (C). Group (A), which contain DSC-1and DSC-2. The first model DSC-1 study the parameter of increasing the upper plate thickness and the second DSC-2 study the parameter of increasing lower plate thickness.

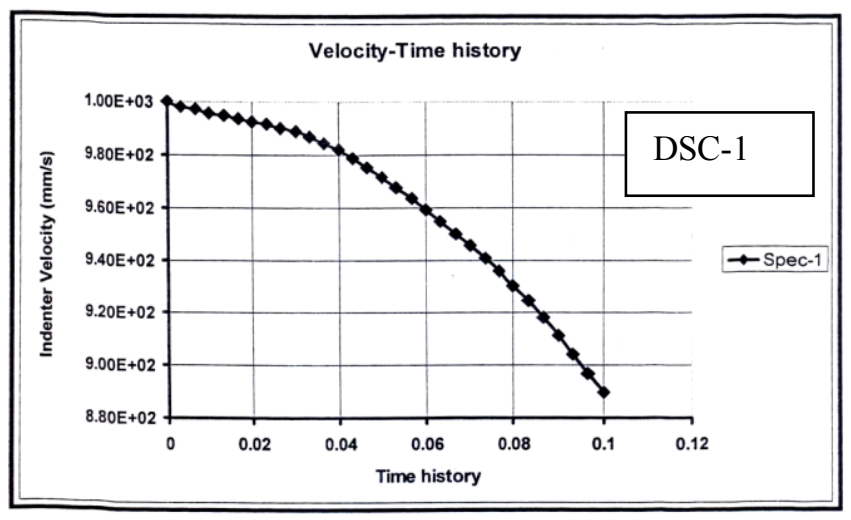

Fig.11 Velocity Time history of DSC- 1

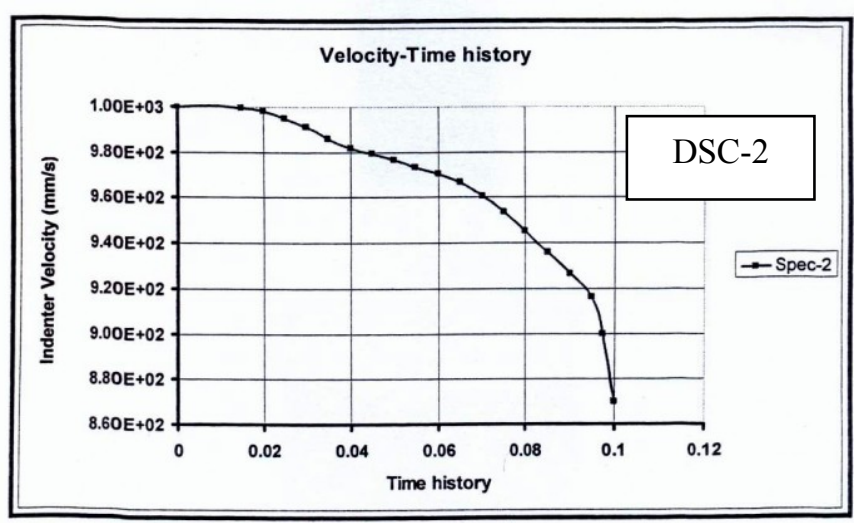

Fig.12 Velocity Time history of DSC- 2

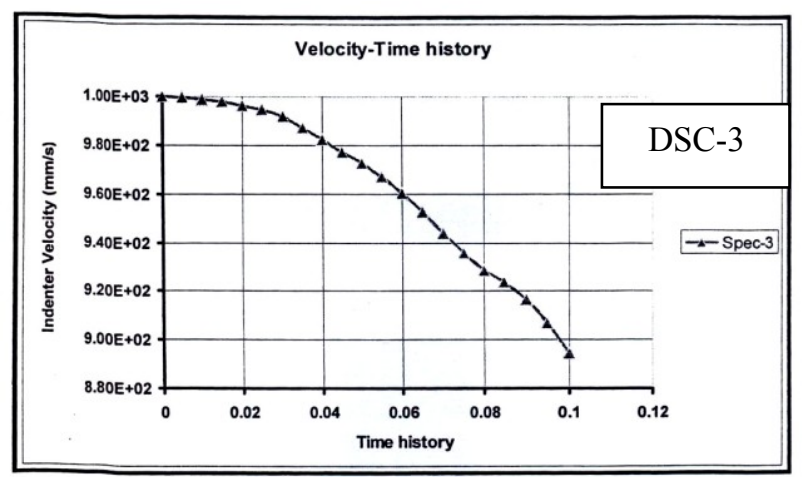

Fig.13 Velocity Time history of DSC- 3 


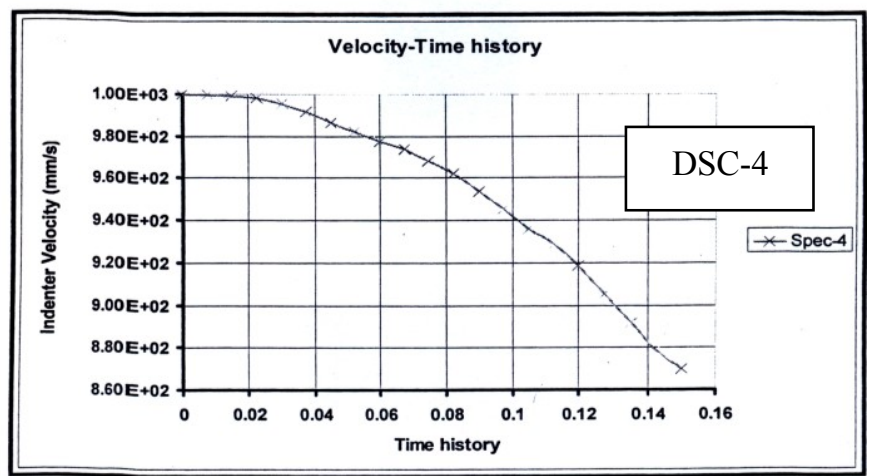

Fig.14 Velocity Time history of DSC- 4

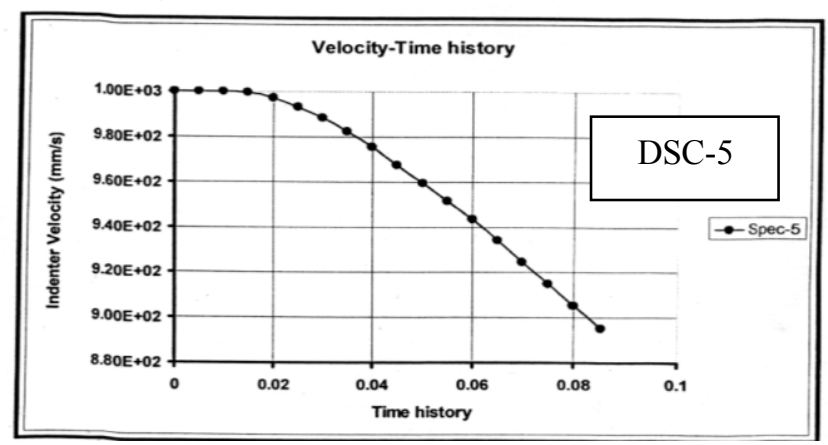

Fig.15 Velocity Time history of DSC- 5

Group (B), which contain DSC-3 and DSC-4. DSC-3 study the parameter of increasing degree of the upper shear stud interaction while DSC-4 study the parameter of increasing the degree of lower shear stud interaction. Group (C), which contain DSC-3 and DSC-5. DSC-5 studies the parameter of verifying the same degree of upper interaction of DSC-3 but with less number of upper shear studs.

Results of group (A) showed that increasing the upper plate thickness from $2 \mathrm{~mm}$ to $4 \mathrm{~mm}$ did not give a valuable effect compared with increasing the lower plate by the same ratio because impact energy caused rapid failure by the great flip of energy of mass. It has a good effect of preventing any possible spalling of upper concrete face. Increasing lower plate thickness by the same ratio increase the absorbed energy by $15 \%$ relative to the energy absorbed in case of DSC-1 as shown in Figure (16).

Results of group (B) shown in Figure (17) explain that, increasing upper degree of interaction has a less valuable effect in enhancing ballistic limit compared with the same increasing ratio of the lower plate degree of interaction. Increasing ratio in lower plate interaction enhanced ballistic limit by $25 \%$ relative to the ratio of increasing in upper plate interaction.

Results of group (C), as shown in Figure (18) explain that no change in ballistic velocity value occurs when the shear connectors in the upper plate are concentrated close to the middle of the plate. Change in stress contours plotted for upper plate of DSC-5 is noticed because of the upper plate buckling near supports as shown in Figure (19). Adequate number of upper studs must be verified to ensure that no additional stresses due to buckling deformations may be propagated. Figure (20) shows global comparison of all specimens' results.

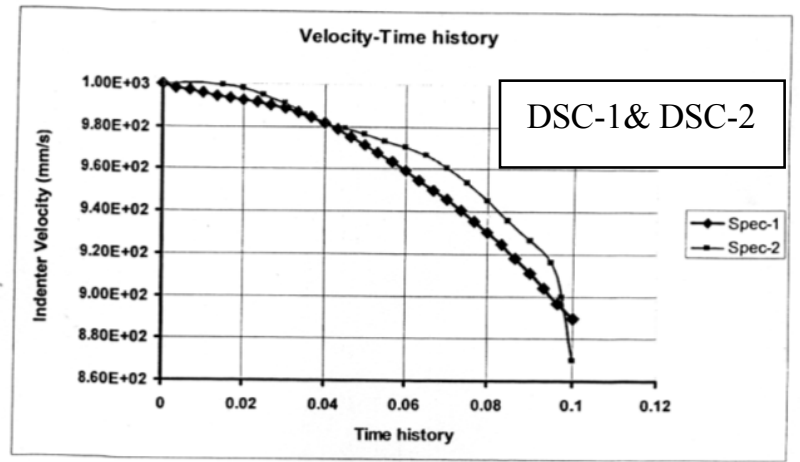

Fig.16 Effect of increasing upper plate thickness (Group A) 


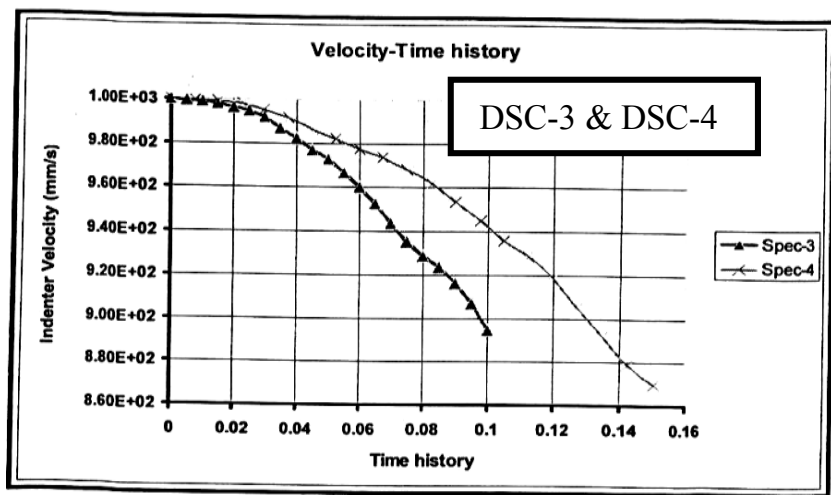

Fig.17 Effect of increasing number of studs in DSC-3 and DSC-4 (Group B)

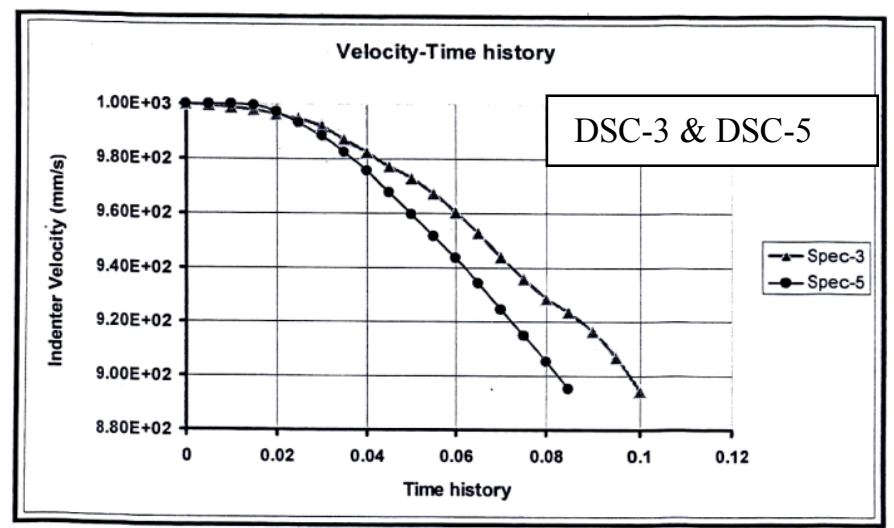

Fig.18Effect of increasing number of studs in DSC-3 and DSC-5 with different stud distribution density (Group C)

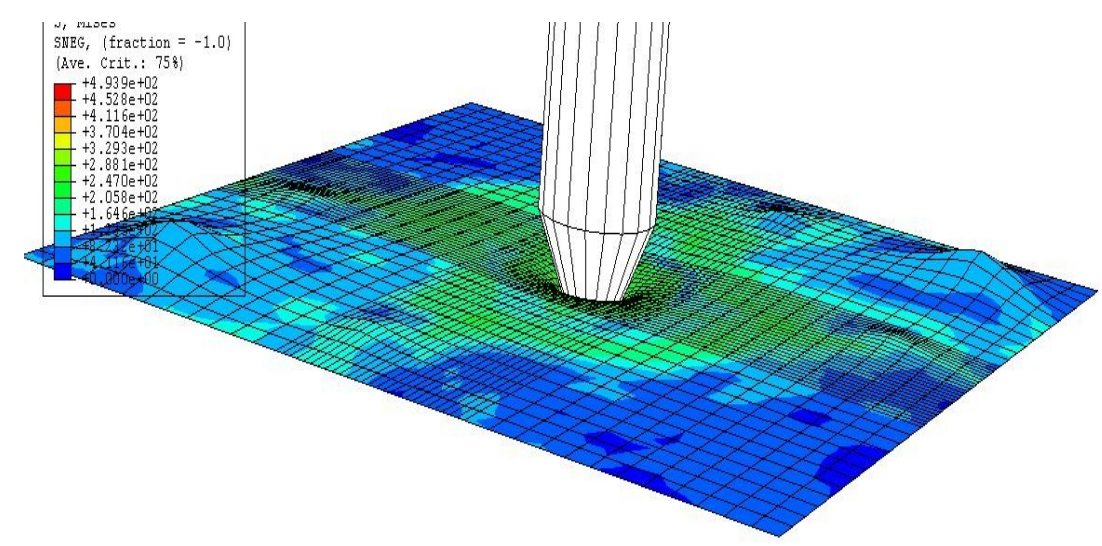

Fig.19 Buckling deformation of upper plate of DSC-5NDue to small number of studs 


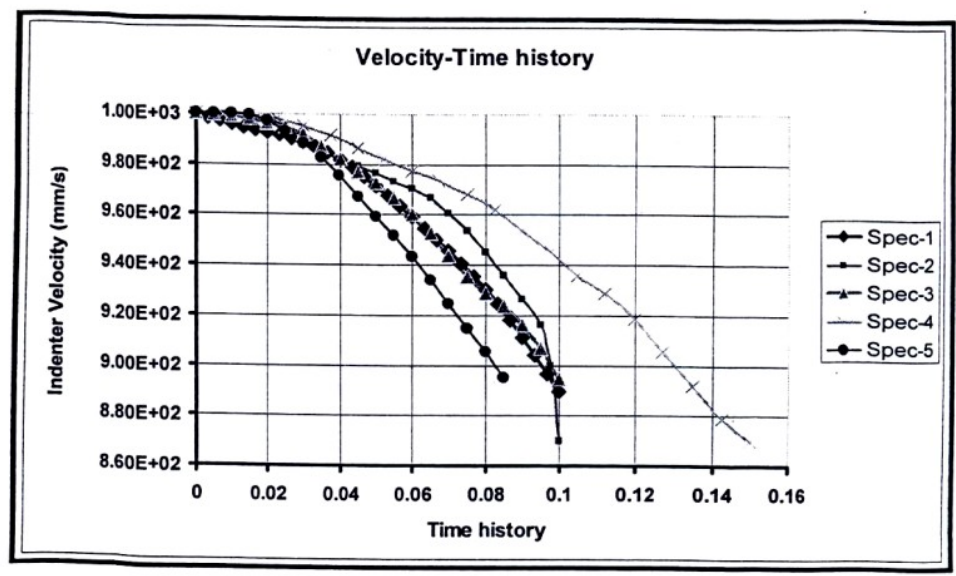

Fig.20 Comparison of results for all models (from DSC-1 to DSC- 5)

For more analysis on the effect of upper and lower plate thickness, the thickness of upper plate of DSC1 is increased from $4 \mathrm{~mm}$ to $6 \mathrm{~mm}$ and the thickness of lower plate of DSC-2 is increased from $4 \mathrm{~mm}$ to $6 \mathrm{~mm}$. Results showed that an increasing by about $24 \%$ of energy absorbed by panel due the change of upper plate thickness as shown in Figure (21). The recorded results of increasing lower plate thickness from $4 \mathrm{~mm}$ to $6 \mathrm{~mm}$ shows a great effect on energy absorbed which increased by 35\% as shown in Figure (22). These results verified the great role of lower plate skin due to its double effect in preventing any scabbing of concrete lower surface (rear surface of impact) which maximizes the resistance of concrete and provides the ductility required in resisting penetration. Much increase in upper plate stiffness helps slightly in absorbing energy due to its role as casing of concrete front face against impact which prevents spalling. The same increase in the lower plate stiffness will be more effective.

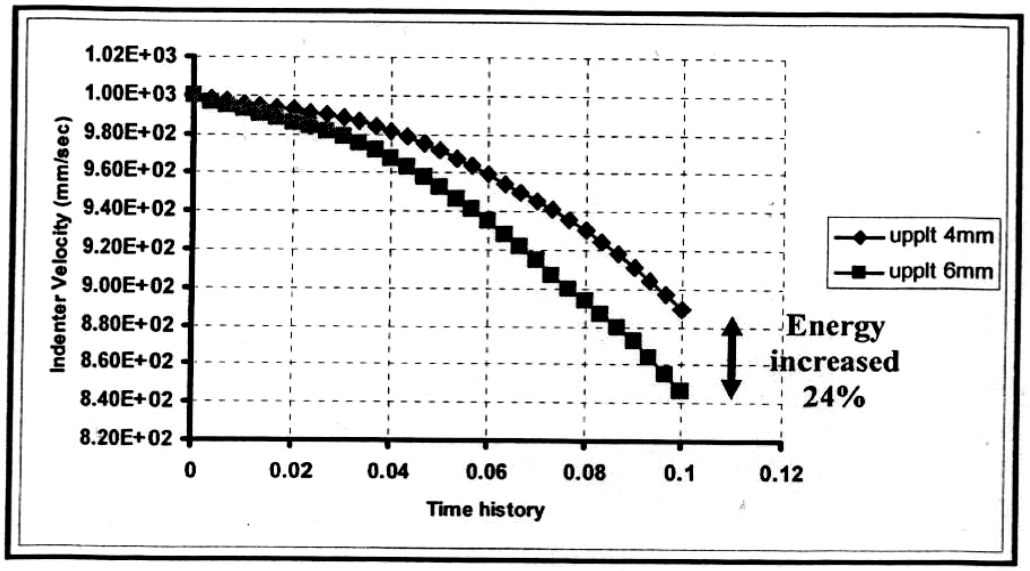

Fig.21 Effect of increasing upper plate thickness of DSC-1 from 4 to $6 \mathrm{~mm}$ 


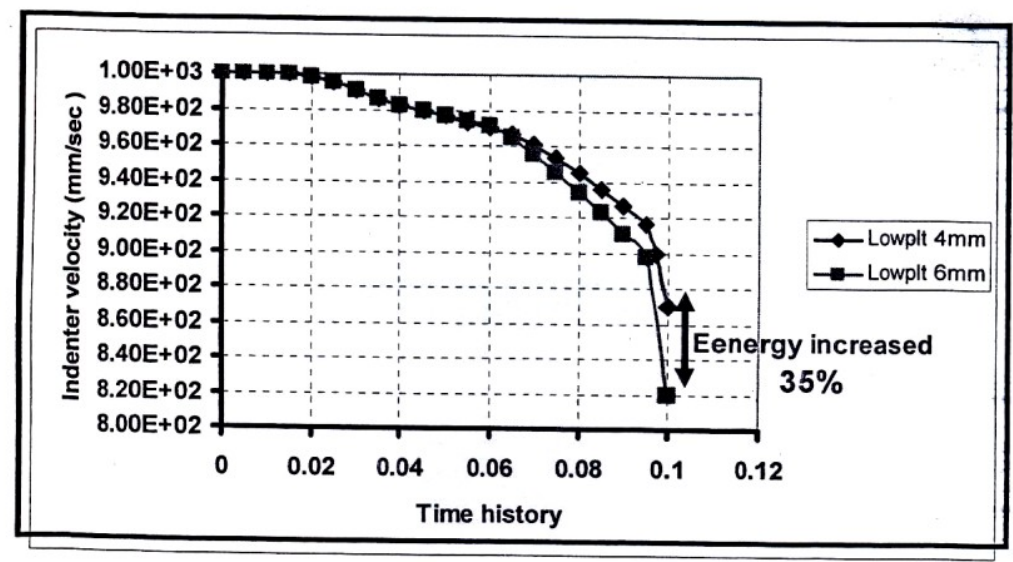

Fig.22 Effect of increasing lower plate thickness of DSC-2 from 4 to $6 \mathrm{~mm}$

\section{Conclusion}

Double skin composite steel and concrete panels are good and efficient elements for resisting low velocity impact due to its great toughness and ductility compared to concrete panels. Increasing of the upper plate thickness to face impact loading give less effect on the energy absorbed compared with increasing the lower plate thickness by the same ratio while it represent excellent solution for problem of front face spalling. Effect of increasing the lower plate thickness has a great and main role in controlling the amount of energy absorbed by such structures due to its ability to prevent concrete scabbing from impact rear face which relaxes strain rate of concrete while resisting penetration and due to the presence of lower shear studs. Increasing amount of shear interaction in lower plate enhances the absorbed energy by about $25 \%$. Results showed that such elements have great ability of absorbing energy when subjected to perforation due to the ductility of the lower skin plate and vertical stiffness of lower shear studs. More investigation and experimental work of the proposed models must be extended for this research in future.

\section{References}

[1] Kennedy, R. P., "A review of the procedures for the analysis and design of concrete structures to resist missile impact effects ", Journal of Nuc. Eng. and Design, No. 37, pp183-203, (1976).

[2] Wright, H.D, Oduyemi, T.O.S and Evans, H.R. "The experimental behavior of double skin composite elements ", J. of constructional steel researches, No. 19, pp 97-110, (1991).

[3] Wright, H.D, Oduyemi, T.O.S and Evans, H.R. "The design of double skin composite elements", Journal of constructional steel researches No. 19, pp 111-132, (1991).

[4] Roberts, T. M., Edwards, D. N. and Narayanan, R., "Testing and analysis of steel-concrete-steel sandwich beams", Journal of constructional steel researches pp 257-279, (1996).

[5] Shanmugam, N. E., Ghanshyam Kumar and Thevendran, V, "Finite element modeling of double skin composite slabs", Journal of finite element in analysis and design, No.38, pp 579-599, (2002).

[6] Xie, M., Foundoukos, N. and Chapman, J.C., "Experimental and numerical investigation on the shear behaviour of friction welded bar-plate connections embedded in concrete", J. of constructional steel research, vol. 61, No. 5, pp625-649, (2005).

[7] Perry, S. H., Brown, I. C \& Dinic, G., "In structural impact and crashworthiness", Elsevier Applied Science, Vol. 2, pp. 617-627, (1984).

[8] Corbett, G.G. \& Reid, S. R., "Local loading of simply-supported steel-grout sandwich plates". Int. J. of Impact Engng., vol. 13, pp. 443-461, (1993)

[9] Corbett, G.G., Reid, S.R. \& Al-Hassani, S.T., "Resistance of steel-concrete sandwich tubes to penetration". Int. J. of Impact Engng., vol. 9, 191-203, (1990).

[10] Naik,N. K. \& Shrirao, P., "Composite structures under ballistic impact", J. of composite structures, No. 66 ,pp 579-590, (2004).

[11] Mohamadien, A.R., Agour, A.A., Omer, A.A. and Yones, M.M." Quasi static indentation of double skin composite panels", 12th International Conference on Aerospace Sciences \& Aviation Technology, MTC, Egypt, pp 1-12, (2007)

[12] Mohamedien, A.R.., Omer, A.A, "Finite elements modeling and Analysis of Double Skin Composite Plates", IOSR Journal of Mechanical and Civil Engineering, vol. 6, Issue 5, pp14-25, (2013).

[13] British Standard Institution, Structural use of concrete, BS 8110: part I, London, 1997. 